\title{
HELPING THE YANOMAMI
}

Purchasing this book new has important implications: all royalties from the book go to assisting the Yanomami. There are no royalties for the Yanomami if you purchase the book used. (How the royalties are allocated-to which parties in which amounts - is publicly available on the Public Anthropology Web site [www.publicanthropology.org].)

Here is a small but significant way to help the Yanomami that extends beyond good intentions. Your commitment to provide the Yanomami with royalties, combined with similar commitments from others, means that the Yanomami will to some degree benefit from the controversy that has swirled around them and disrupted their lives. 


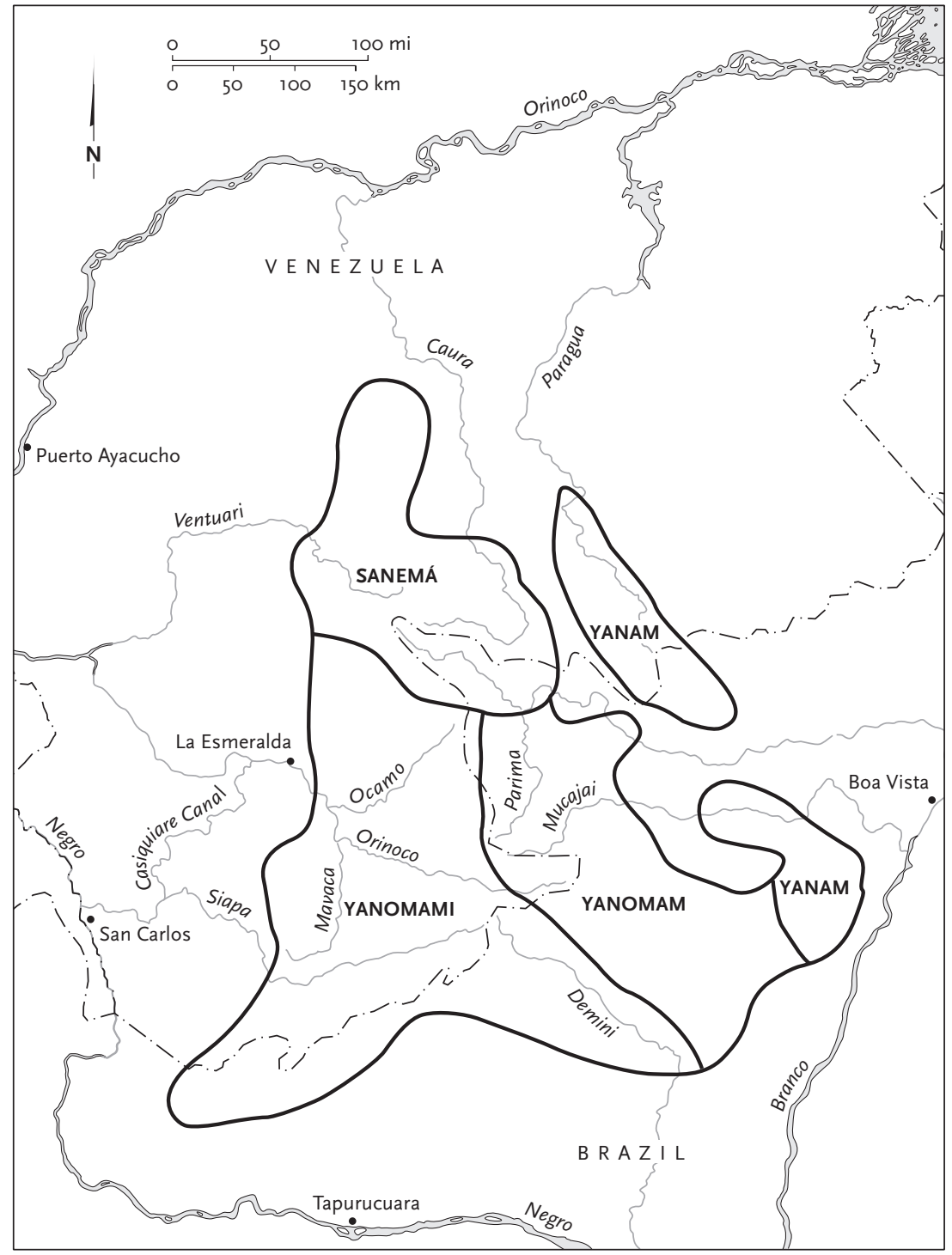

The area where the Yanomami live in southern Venezuela and northern Brazil with the names and locations of the most prominent Yanomami subgroups. (This map is drawn from Roberto Lizarralde's Grupos Lingüísticos Yanomami, prepared for the Venezuelan government's census.) 